\title{
Acute Phase Complications of Older Children with Kawasaki Disease
}

\author{
Toshimasa Nakada ${ }^{1}$ \\ ${ }^{1}$ Department of Pediatrics, Aomori Prefectural Central Hospital, T030-8553 Higashi- tukurimiti 2-1-1, Aomori City, Aomori Prefecture, Japan.
}

\section{Abstract}

Background: Older children with Kawasaki disease (KD) have a risk for acute phase complications including coronary artery lesions (CALs). Objective: To clarify the frequency and outcomes of acute phase complications in older children who received an initial single intravenous immunoglobulin (IVIG) therapywith delayed use of aspirin. Subjects and Methods: This retrospective study included data from 216 consecutive patients who underwent initial single IVIG therapy at $2 \mathrm{~g} / \mathrm{kg}$ with DUA. The data were divided into a group for cases aged 5 years or older (older group, $\mathrm{n}=34$ ) and another group for cases aged $<5$ years (younger group, $\mathrm{n}=182$ ). Statistical analyses were performed using Chi-square, Fisher's exact, and Mann-Whitney U tests as appropriate. Results: Six of 34 (17.6\%) older group patients were associated with complications ( 2 with CAL and 4 with non-cardiac complications required treatment). The non-cardiac complications included arthritis, transient blindness, and atlantoaxial rotatory fixation. All of these non-cardiac complications were recovered after treatment. The rate of CAL in older group patients was similar to that in younger group patients $(5.9 \%$ vs. $1.6 \%, \mathrm{P}=0.177)$. However, the rate of non-cardiac complications in the former was significantly higher than that of the latter $(11.8 \%$ vs. $0.0 \%, \mathrm{P}<0.001)$. Conclusion: Whereas the older children who underwent initial single IVIG therapy at $2 \mathrm{~g} / \mathrm{kg}$ with DUA have the higher risk for non-cardiac complications compared to the younger patients, the rate of CAL was similar between the older and younger children.

Keywords: Kawasaki Disease, Complications, Older Children, Intravenous Immunoglobulin Therapy, Aspirin.

Corresponding Author: Dr. Toshimasa Nakada, Department of Pediatrics, Aomori Prefectural Central Hospital, T030-8553 Higashitukurimiti 2-1-1, Aomori City, Aomori Prefecture, Japan.

Received: September 2019

Accepted: September 2019

\section{Introduction}

Kawasaki disease $(\mathrm{KD})$ is an acute systemic vasculitis of unknown origin that majorly affects children. ${ }^{[1]}$ Coronary artery lesions (CALs) are a severe KD complication. Furthermore, non-cardiac complications including arthritis and blindness have been reported among KD patients. ${ }^{[2,3]}$ Older children with KD who received initial IVIG therapy with concomitant use of aspirin have a risk for acute phase complications including both CAL and non-cardiac complications. $^{[2-5]}$

At present, the standard therapy for the acute phase of this disease is intravenous immunoglobulin (IVIG) therapy at 2 $\mathrm{g} / \mathrm{kg} / \mathrm{dose}$ with the concomitant use of medium- or higherdose aspirin. ${ }^{[6]}$ However, the concomitant use of medium- or higher-dose aspirin is now controversial. ${ }^{[7]} \mathrm{A}$ randomized controlled trial regarding the effectiveness of intravenous immunoglobulin alone and intravenous immunoglobulin combined with high-dose aspirin in the acute stage of KD is ongoing. ${ }^{[8]}$ Recent studies have suggested that aspirin may inhibit CAL prevention. ${ }^{[9,10]}$ The delayed use of aspirin (DUA) may bebeneficial for the prevention of coronary artery stenosis in KD. ${ }^{[9,11-13]}$ This study aimed to clarify the frequency and outcomes of acute phase complications in older children who received an initial single IVIG therapy $(2 \mathrm{~g} / \mathrm{kg})$ with DUA.

\section{Subjects and Methods}

The study protocol was approved by our institutional ethics committee and the requirement of patient consent was waived.

This retrospective study included data from 216 consecutive patients who underwent initial single IVIG therapy at 2 $\mathrm{g} / \mathrm{kg} / \mathrm{dose}$ with DUA for KD from January 2004 to May 2019 at our department. The data of these patients were collected retrospectively. The data were divided into a group for cases aged 5 years or older (older group, $\mathrm{n}=34$ ) and another group for cases aged $<5$ years (younger group, $\mathrm{n}=182$ ). The diagnosis of KD was established based on the criteria (Japanese, fifth edition) mentioned in the diagnostic guidelines for KD. ${ }^{[14]}$ Patients with a first episode of KD were included. Five patients with CAL before therapy, and one patient with status epilepticus at the first presentation who received the combined therapy with initial IVIG and steroid were excluded. Another patient who developed left ventricular dysfunction and underwent a different protocol using plasma exchange in the early stage was excluded.

IVIG resistance was defined as fever that persisted or reappeared at 24 hours after first line treatment. ${ }^{[15]}$ The Egami score, a risk score for predicting IVIG-resistance based on clinical findings such as age, illness days, platelet count, alanine aminotransferase level, and C-reactive 
protein level, was evaluated before the initial IVIG therapy. ${ }^{[16]}$

\section{Initial therapy}

During the study period, an initial single IVIG regimen of 2 $\mathrm{g} / \mathrm{kg} /$ dose, starting on day 5 of the illness, was used as firstline therapy, whenever possible.

Between January 2004 and November 2017, antiinflammatory drugs (aspirin or flurbiprofen) were initiated within 24 hours after the end of initial IVIG infusion. Aspirin was initiated at a dose of $30 \mathrm{mg} / \mathrm{kg} /$ day and decreased to $5-10 \mathrm{mg} / \mathrm{kg} /$ day when the patient became afebrile. Flurbiprofen was initiated at a dose of 3-5 $\mathrm{mg} / \mathrm{kg} /$ day and decreased to $3 \mathrm{mg} / \mathrm{kg} /$ day when the patient became afebrile. ${ }^{[9]}$ The choice between aspirin and flurbiprofen was made by each doctor after considering the patient's liver function and risk of Reye syndrome during the influenza season.

A regimen of initial IVIG therapy with delayed use of antiinflammatory drugs was used after 2004. Some patients received this therapy with delayed use of anti-inflammatory drugs between 2004 and 2008. The choice between delayed use of anti-inflammatory drugs and concomitant use of antiinflammatory drugs was made by the individual doctors during this period. After 2009, initial IVIG therapy with delayed use of anti-inflammatory drugs was utilized for all patients until November 2017. ${ }^{[9,12]}$ After December 2017, low-dose aspirin $(5 \mathrm{mg} / \mathrm{kg} /$ day $)$ was initiated at 8 th to 10 th day of illness after completion of IVIG infusion including 2nd therapy. ${ }^{[13]}$

\section{Rescue therapy}

The decision to use rescue therapies in resistant patients was made between 48 and 72 hours after the initial IVIG therapy was completed. The decision was made comprehensively according to individual clinical variables that included body temperature, major KD symptoms, general condition, and laboratory data. The second-line therapy was rescue IVIG therapy at $2 \mathrm{~g} / \mathrm{kg}$, and the third-line therapy consisted of ulinastatin infusion, third IVIG therapy, or plasma exchange. ${ }^{[13]}$

\section{Diagnosis of CAL}

CAL was diagnosed using echocardiography based on the Japanese criteria according to the study by Kobayashi et al. ${ }^{[17]} \mathrm{CAL}$ was diagnosed when any of the examinations showed an internal lumen diameter $\geqq 3 \mathrm{~mm}$ in a patient $<5$ years old or a diameter $\geqq 4 \mathrm{~mm}$ in a patient $\geqq 5$ years old, if the internal diameter of a segment was at least 1.5 times that of an adjacent segment, or if the lumen appeared irregular. Transient CAL was defined as the disappearance of CAL within 30 days of the illness.

\section{$\underline{\text { Statistical analysis }}$}

Statistical analyses were performed using Stat Flex Version 6 for Windows (Artech Co.,

Ltd., Osaka, Japan). Chi-square, Fisher's exact, and MannWhitney $U$ tests were used as appropriate, with sample size considerations. A value of $\mathrm{P}<0.05$ was considered statistically significant.

\section{Results}

Six of $34(17.6 \%)$ older group patients were associated with complications ( 2 patients with CAL and 4 patients with non-cardiac complications required treatment) [Table 1].

One of the 2 patients with CAL had the transient CAL with maximum internal diameter of $3.7 \mathrm{~mm}$ at the $8^{\text {th }}$ day of illness. The CAL regressed at the $12^{\text {th }}$ day of illness. Another patient had the CAL with maximum internal diameter of $5.3 \mathrm{~mm}$ before $30^{\text {th }}$ day of illness. The CAL persisted and the selective coronary arteriogram at one year after KD onset revealed a solitary medium-sized aneurysm without stenosis in the mid-portion of the right coronary artery.

The non-cardiac complications included arthritis, transient blindness, and prolonged restriction of cervical movement caused by atlantoaxial rotatory fixation (AARF) [Table 2]. Additional treatments were required in all patients with non-cardiac complications. One of two patients with arthritis received corticosteroid treatment as 4th line therapy [Table 2]. All of these non-cardiac complications were recovered after treatment. The arthritis in 2 patients were self-limited and left no sequelae.

The prevalence of incomplete type and Egami scores were similar between the patients in the older and the younger group patients [Table 3]. The rate of CAL in older group patients was similar to that in younger group patients $(5.9 \%$ vs. $1.6 \%, \mathrm{P}=0.177$ ) [Table 3]. However, the rate of noncardiac complications in the former was significantly higher than that of the latter $(11.8$ vs. $0.0 \%, \mathrm{P}<0.001)$ [Table 3 ].

Table 1: Demographic data of the 34 older group patients.

\begin{tabular}{|l|l|}
\hline Variables & Data \\
\hline Gender & 17 boys (50\%) and 17 girls (50\%) \\
\hline Age & $\begin{array}{l}\text { Median: 6 years, 4.5 months (age range, } \\
5 \text { years-13 years, 3 months) }\end{array}$ \\
\hline Incomplete type & 4 patients (12\%) \\
\hline $\begin{array}{l}\text { Low-dose aspirin/medium- } \\
\text { dose aspirin/flurbiprofen }\end{array}$ & $\begin{array}{l}\text { 4 patients (12\%)/19 patients (56\%)/11 } \\
\text { patients (32\%) }\end{array}$ \\
\hline $\begin{array}{l}\text { Start time of initial IVIG } \\
\text { therapy }\end{array}$ & $\begin{array}{l}\text { Median: the fifth day of illness (range, } \\
\text { day 4-13 of illness) }\end{array}$ \\
\hline Initial IVIG therapy resistance & 12 patients (35\%) \\
\hline $\begin{array}{l}\text { Rescue IVIG therapy for initial } \\
\text { IVIG resistance }\end{array}$ & 6 patients (17.6\%) \\
\hline $\begin{array}{l}\text { Third-line therapy for } \\
\text { resistance }\end{array}$ & $\begin{array}{l}1 \text { patient (2.9\%) received ulinastatin } \\
\text { infusion. }\end{array}$ \\
\hline Complications 6 patients (17.6\%) \\
\hline Coronary artery lesions & 2 patients (5.9\%) \\
\hline $\begin{array}{l}\text { Non-cardiac complications } \\
\text { required therapies }\end{array}$ & 4 patients (11.8\%) \\
\hline \multicolumn{2}{|l}{ IVIG, intravenous immunoglobulin. } \\
\hline
\end{tabular}


Table 2: Complications and treatment of the older group patients

\begin{tabular}{|l|l|l|}
\hline Complications & $\begin{array}{l}\text { Numbers } \\
\text { of } \\
\text { patients }\end{array}$ & Treatment \\
\hline Coronary artery lesions & $\begin{array}{l}\text { Second IVIG therapy for 2 } \\
\text { patients }\end{array}$ \\
\hline Before 30 day of illness & 2 patients & \\
\hline After 30 day of illness & 1 patient & \\
\hline Non-cardiac complications & 2 patients & $\begin{array}{l}\text { Second IVIG therapy for 2 } \\
\text { patients, Ulinastatin and } \\
\text { steroids for 1 patient }\end{array}$ \\
\hline Arthritis & $\begin{array}{l}\text { Second IVIG therapy, } \\
\text { Topical } \beta \text {-blocker and } \\
\text { topical steroids }\end{array}$ \\
\hline $\begin{array}{l}\text { Ocular complications (uveitis, } \\
\text { increased intraocular pressure, } \\
\text { possible optic perineuritis) }\end{array}$ & 1 patient \\
\hline $\begin{array}{l}\text { Atlantoaxial rotatory fixation } \\
\text { IVIG, intravenous immunoglobulin. }\end{array}$ & 1 patient & $\begin{array}{l}\text { Second IVIG } \\
\text { therapy,Glisson traction }\end{array}$ \\
\hline
\end{tabular}

Table 3: Comparison of clinical findings between the patients in the older and younger groups

\begin{tabular}{|c|c|c|c|}
\hline Variables & $\begin{array}{l}\text { Older group } \\
(\mathbf{n}=\mathbf{3 4})\end{array}$ & $\begin{array}{l}\text { Younger group } \\
(\mathbf{n}=182)\end{array}$ & $\begin{array}{l}\mathbf{P} \\
\text { value }\end{array}$ \\
\hline Gender: male patients & $17(50 \%)$ & $96(53 \%)$ & 0.768 \\
\hline Age (months) & $\begin{array}{l}76.5(66.0- \\
99.0)\end{array}$ & $22.0(12.0-34.0)$ & $\begin{array}{l}< \\
0.001\end{array}$ \\
\hline Incomplete type & $4(12 \%)$ & $24(13 \%)$ & 1.000 \\
\hline Egami score & $1.5(1.0-2.0)$ & $1.0(1.0-2.3)$ & 0.823 \\
\hline $\begin{array}{l}\text { Low-dose } \\
\text { aspirin/medium-dose } \\
\text { aspirin/flurbiprofen }\end{array}$ & $\begin{array}{l}4(12 \%) / 19 \\
(56 \%) / 11 \\
(32 \%) \\
\end{array}$ & $\begin{array}{l}25(14 \%) / 83 \\
(46 \%) / 74(41 \%)\end{array}$ & 0.542 \\
\hline $\begin{array}{l}\text { Timing of initial IVIG } \\
\text { therapy (day of illness) }\end{array}$ & $5(5-6)$ & $5(5-6)$ & 0.502 \\
\hline Resistant patients & $12(35 \%)$ & $40(22 \%)$ & 0.096 \\
\hline $\begin{array}{l}\text { Rescue therapy for } \\
\text { resistance }\end{array}$ & $6(17.6 \%)$ & $16(8.8 \%)$ & 0.127 \\
\hline $\begin{array}{l}\text { Rescue therapy for } \\
\text { relapse }\end{array}$ & $0(0.0 \%)$ & $5(2.7 \%)$ & 0.598 \\
\hline Complications & $6(17.6 \%)$ & $3(1.6 \%)$ & $\begin{array}{l}< \\
0.001\end{array}$ \\
\hline \multicolumn{4}{|l|}{ Coronary artery lesions } \\
\hline Before 30 day of illness & $2(5.9 \%)$ & $3(1.6 \%)$ & 0.177 \\
\hline After 30 day of illness & $1(2.9 \%)$ & $1(0.5 \%)$ & 0.291 \\
\hline $\begin{array}{l}\text { Non-cardiac } \\
\text { complications }\end{array}$ & $4(11.8 \%)$ & $0(0.0 \%)$ & $\begin{array}{l}< \\
0.001\end{array}$ \\
\hline
\end{tabular}

\section{Discussion}

Whereas the older children who underwent initial single IVIG therapy at $2 \mathrm{~g} / \mathrm{kg} /$ dose with DUA have the higher risk for non-cardiac complications compared to the younger patients, the rate of CAL was similar between the older and younger children. An onset at an older age is an independent risk factor for the development of cardiovascular sequelae in $\mathrm{KD} .{ }^{[4]}$ The prevalence of CAL is higher in older children than in younger children. ${ }^{[5]}$ The present study suggested that an initial IVIG therapy of 2 $\mathrm{g} / \mathrm{kg} / \mathrm{dose}$ with DUA may be useful for suppression of CAL caused by KD in older children.
The use of IVIG therapy with DUA may be beneficial for the prevention of coronary artery stenosis in KD. ${ }^{[13]}$ The delayed use of low-dose aspirin has been shown to reduce the incidence of large CAL caused in KD. ${ }^{[11]}$ It has been suggested that the concomitant use of an anti-inflammatory drug may exert an inhibitory effect on the initial IVIG therapy at $2 \mathrm{~g} / \mathrm{kg} / \mathrm{dose}^{\left[{ }^{[12]}\right.}$ Thus, patients receiving an initial IVIG with delayed use of anti-inflammatory drugs may delay that inhibitory effect deemed adverse during the initial stages. Therefore, the combination order and timing of initial IVIG therapy with administration of antiinflammatory drugs may be important to achieve the best outcome and inhibit the development of $\mathrm{CAL}^{[12]}$ No patients underwent initial single IVIG therapy at 2 $\mathrm{g} / \mathrm{kg} / \mathrm{dose}$ with DUA in this study were associated with CAL leaving stenotic lesions.

Delay in diagnosis and treatment are thought to be a factor for poor outcomes in older children with $\mathrm{KD} .{ }^{[18]}$ In the present study, the median start time of initial IVIG therapy in the older children was the fifth day of illness (range, day 4-13 of illness). This finding suggests that the appropriate timing of start time of initial treatment may lead to favorable outcomes of older children with KD.

Apart from CAL, KD may present with non-cardiac complications in multiple body systems during acute phase ${ }^{[19]}$ Previous studies showed that the older children have a risk of non-cardiac complications including arthritis, ocular complications, and AARF during acute phase of KD. ${ }^{[2,3,20]}$ Those findings were consistent with the present study in the patients who received initial IVIG therapy with DUA.

Two patients were associated with arthritis in the present study. The prevalence of arthritis in the acute phase of KD was $7.5 \%$ to $10.6 \% .^{[2,21]}$ Most cases of arthritis resolve without additional therapeutic intervention. ${ }^{[21]} \mathrm{A}$ Chinese cohort study with regard to arthritis in KD showed that the clinical course of arthritis was short-lived in most patients, and that no additional anti-inflammatory drug was needed in these patients. ${ }^{[2]}$ On the other hand, another study showed that rescue therapy including corticosteroid treatment was necessary in $13 \%$ of the patients with arthritis in $\mathrm{KD} \cdot{ }^{[21]} \mathrm{In}$ the present study, 2 patients with arthritis required the second round of IVIG therapy, and one of these patients required corticosteroid treatment as 4th line therapy. This patient with intractable arthritis was initial IVIG therapyresistant and had high values of inflammatory biomarkers after initial therapy. ${ }^{[22]}$ The additional therapy including corticosteroid treatment may be required in intractable arthritis in KD. A study showed that the arthritis in KD was self-limited and left no sequelae. ${ }^{[2]}$ This finding was consistent with that in the present study.

A study disclosed the higher incidence rate of coronary artery aneurysms among patients with arthritis in $\mathrm{KD}$ (7.28\%) compared to those without arthritis $(2.75 \%)(\mathrm{P}=$ $0.003){ }^{[2]}$ On the other hand, another study showed that children with arthritis in KD share the same clinical features including coronary outcomes. ${ }^{[21]}$ In the present study, 2 patients with arthritis were not associated with CAL. The different findings with regard to the relations between 
arthritis and CAL in KD patients are thought to be due to the different region, ethnicity, and sample size of the studies. ${ }^{[2]}$ The difference of the acute phase treatment for KD may be another factor for different outcomes in patients with arthritis in KD.

Older children may have a higher risk of blindness and ocular posterior segment involvement in the acute phase of $\mathrm{KD} \cdot{ }^{[3]}$ Ocular involvement in the acute phase of $\mathrm{KD}$ typically involves the anterior segment of the eye, and its associated treatment outcomes are generally excellent. However, there are rare reports of posterior segment involvement, and these are associated with poorer outcomes. ${ }^{[3,23,24]}$ The persistent inflammation caused by KD may lead to ocular posterior segment involvement. ${ }^{[24]}$ The causes of transient blindness of the patient in the present study were thought to be compression of the optic disc via increased intraocular pressure due to uveitis and possible subclinical optic perineuritis. ${ }^{[22]}$

AARF is a rare complication of KD. ${ }^{[20]} \mathrm{A}$ study showed that the median age of the patients with AARF during acute phase of KD was 6 years. ${ }^{[20]}$ AARF is frequently observed in infants and school-age children; some reasons for this may include features pertaining to physical development and anatomy in children, such as insufficient bony structural support, loose capsule and large torsion angle as well as large proportion of soft tissue in atlantoaxial joint and direct connection of the pharyngeal lymph vessels to the venous plexus. These features predispose children to being susceptible to inflammation of atlantoaxial joint. ${ }^{[25]}$ Inflammatory processes of $\mathrm{KD}$ at the neck might cause ligament hypermobility, with distension and abnormal laxity of ligaments surrounding the neck articulation and sternomastoid spasm. ${ }^{[20]}$ The patient with AARF in the present study was initial IVIG-resistant. Persistent inflammation after initial therapy might be the predisposing factor of the prolonged restriction of cervical movement caused by AARF.

The limitations of this study included the inclusion of a small number of older group patients and the retrospective study design.

\section{Conclusion}

Whereas the older children who underwent initial single IVIG therapy at $2 \mathrm{~g} / \mathrm{kg} /$ dose with DUA have the higher risk for non-cardiac complications compared to the younger patients, the rate of CAL was similar between the older and younger children. Previous studies showed that the older children who received initial IVIG therapy with concomitant use of aspirin have a risk of both CAL and non-cardiac complications during acute phase of KD.

Outcomes in terms of acute phase complications in older children who received initial IVIG therapy with DUA was different from those who received initial IVIG therapy with concomitant use of aspirin. The present study suggested that an initial IVIG therapy of $2 \mathrm{~g} / \mathrm{kg} / \mathrm{dose}$ with DUA may be useful for suppression of CAL caused by KD in older children.

\section{Acknowledgements}

I would like to thank all of those who were involved in the medical management of the patients included in this study.

\section{References}

1. Burns JC, Glod é MP. Kawasaki syndrome. Lancet 2004; 364(9433): 533-44.

2. Peng Y, Liu X, Duan Z, Deng Y, Cai S, Wang Z, et al. Prevalence and characteristics of arthritis in Kawasaki disease: a Chinese cohort study. Clin Exp Med. 2019 May;19(2):167-172. doi: 10.1007/s10238-019-00547-w.

3. Nakada T. Blindness and ocular posterior segment involvement in the acute phase of Kawasaki disease: a mini-review. IOSR Journal Of Pharmacy 2016; 6(8): 26-29

4. Muta H, Ishii M, Sakaue T, Egami K, Furui J, Sugahara Y, et al. Older age is a risk factor for the development of cardiovascular sequelae in Kawasaki disease, Pediatrics 2004; 114:751-4.

5. Lee KY, Hong JH, Han JW,Lee JS, Lee BC, Burgner D, et al. Features of Kawasaki disease at the extremes of age. J Paediatr Child Health 2006; 42:423-7.

6. McCrindle BW, Rowley AH, Newburger JW, Burns JC, Bolger AF, Gewitz M, et al. Diagnosis, treatment, and long-term management of Kawasaki Disease: A scientific statement for health professionals from the American Heart Association. Circulation 2017; 135: e92799.

7. McCrindle BW, Tierney ESS. Acute treatment for Kawasaki disease: challenges for current and future therapies. J Pediatr 2017; 184: 7-10.

8. Kuo HC, Guo MM, Lo MH, Hsieh KS, Huang YH. Effectiveness of intravenous immunoglobulin alone and intravenous immunoglobulin combined with high-dose aspirin in the acute stage of Kawasaki disease: study protocol for a randomized controlled trial. BMC Pediatr. 2018; 18(1): 200

9. Nakada T. Effects of anti-inflammatory drugs on intravenous immunoglobulin therapy in the acute phase of Kawasaki disease. Pediatr Cardiol 2015; 36: 335-9.

10. Lau AC, Duong TT, Ito S, Yeung RS. Intravenous immunoglobulin and salicylate differentially modulate pathogenic processes leading to vascular damage in a model of Kawasaki disease. Arthritis Rheum 2009; 60: 2131-41.

11. Cho HJ, Bak SY, Kim SY, Yoo R, Baek HS, Yang S,et al. High neutrophil : lymphocyte ratio is associated with refractory Kawasaki disease. Pediatr Int 2017; 59: 669-74.

12. Nakada T: Inhibitory effect of anti-inflammatory drugs on the initial intravenous immunoglobulin therapy $(2 \mathrm{~g} / \mathrm{kg} / \mathrm{dose})$ in Kawasaki disease. International Journal of Advances in Medical Sciences 2018; 3 (5): $1-10$.

13. Nakada T. Acute phase treatment for prevention of coronary artery stenosis caused in Kawasaki disease: a single center retrospective study. J Adv Res Med 2018; 5(4): 1-7.

14. Ayusawa $M$, Sonobe $T$, Uemura $S$, Ogawa S, Nakamura $Y$, Kiyosawa N,et al. Revision of diagnostic guidelines for Kawasaki disease (the 5th revised edition). Pediatr Int 2005; 47: 232-4.

15. Research Committee of the Japanese Society of Pediatric Cardiology; Cardiac SurgeryCommittee for Development of Guidelines for Medical Treatment of Acute Kawasaki Disease. Guidelines for medical treatment of acute Kawasaki disease: report of the Research Committee of the Japanese Society of Pediatric Cardiology and Cardiac Surgery (2012 revised version). Pediatr Int 2014; 56: 13558.

16. Egami K, Muta H, Ishii M, Suda K, Sugahara Y, Iemura M, et al. Prediction of resistance to intravenous immunoglobulin treatment in patients with Kawasaki disease, J Pediatr 2006; 149: 237-40.

17. Kobayashi $\mathrm{T}$, Inoue $\mathrm{Y}$, Takeuchi $\mathrm{K}$, Okada $\mathrm{Y}$, Tamura K, Tomomasa $\mathrm{T}$, et al. Prediction of intravenous immunoglobulin unresponsiveness in patients with Kawasaki disease. Circulation 2006; 113:2606-12.

18. Bresson V, Bonello B, Rousset-Rouvière C, Serratrice J, Chabrol B, Dubus JC, et al. Kawasaki disease in older children and young adults: 10 years of experience in Marseille, France. Arch Pediatr. 2011;18(7):731-6.

19. Alves NRM, Magalhães CMR, Almeida RFR, Santos RCR, Gandolfi 
L, Pratesi R. Prospective study of Kawasaki disease complications: review of 115 cases. Rev. Assoc. Med. Bras. 2011; 57 (3): 295-300.

20. Nozaki F, Kusunoki T, Tomoda Y, Hiejima I, Hayashi A, Kumada T, et al. Grisel syndrome as a complication of Kawasaki disease: a case report and review of the literature. Eur J Pediatr 2013; 172: 119-121.

21. Gong GW, McCrindle BW, Ching JC, Yeung RS. Arthritis presenting during the acute phase of Kawasaki disease. J Pediatr 2006; 148: 800-805.

22. Nakada T: Outcomes of older children with Kawasaki disease who received intravenous immunoglobulin therapy with delayed use of anti-inflammatory drugs. Journal of Advances in Medicine and Medical Research 2017; 22(5): 1-7.

23. Farvardin M, Kashef S, Aleyasin S, Nabavizadeh SH, Sajjadi M,
Safari M. Sudden unilateral blindness in a girl with Kawasaki disease. J Pediatr Ophthalmol Strabismus 2007; 44: 303-304.

24. Grouteau E, Debuisson C, Brochard K, Paranon S, Lesage Beaudon C, Pajot C, et al. Severe global inflammatory involvement of ocular segments and optic disc swelling in a 12-year-old girl with Kawasaki disease. Eur J Ophthalmol 2011; 21: 112-114.

25. Ohtani K, Matsumoto N, Fujimoto M, Inagaki H, Kitsuda K, Kaida $\mathrm{M}$, et al. Atlanto-axial rotatory fixation in children: comparison of clinical findings and outcomes by etiology. J Jpn Ped Orthop Ass 2014; 23: 407-415.

Copyright: (C) the author(s), 2019. It is an open-access article distributed under the terms of the Creative Commons Attribution License (CC BY 4.0), which permits authors to retain ownership of the copyright for their content, and allow anyone to download, reuse, reprint, modify, distribute and/or copy the content as long as the original authors and source are cited.

How to cite this article: Nakada T. Acute Phase Complications of Older Children with Kawasaki Disease. Asian J. Med. Res. 2019;8(3):PE04-PE08.

DOI: dx.doi.org/10.21276/ajmr.2019.8.3.PE2

Source of Support: Nil, Conflict of Interest: None declared. 